First publ. in: Applied Psychology : an International Review ; 54 (2005), 3. -

pp. 355-377

\title{
The Changing Values of Children and Preferences Regarding Family Size in South Africa
}

\author{
David Lackland Sam* \\ University of Bergen, Norway \\ Karl Peltzer \\ University of Limpopo and Human Sciences Research Council, \\ Pretoria, South Africa \\ Boris Mayer \\ University of Konstanz, Germany
}

\begin{abstract}
Cette recherche élargit à un contexte africain avec la problématique suivante les études en cours sur les relations entre les générations et les valeurs attribuées aux enfants: dans quelle mesure la structure des valeurs projetées sur les enfants (VOC) repérée dans des études antérieures peut-elle être retrouvée en Afrique du Sud et quelles sont les préférences des femmes concernant la taille des familles petite, nombreuse et idéale. L'échantillon était constitué de trois cohortes de femmes noires sud-africaines originaires de la province de Limpopo. Des analyses factorielles ont montré que les dimensions de la VOC apparue en Afrique du Sud étaient un agrégat de différentes valeurs. Ont été isolées comme dimensions relatives au désir d'enfants Social/Emotionnel et Traditionnel/Utilitaire. Pour ce qui est des motifs expliquant le choix de ne pas avoir d'enfants sont apparus «l'enfant comme source de contraintes $\gg$ et $\ll$ les contraintes que constitue le fait d'avoir un enfant $\gg$. Les comparaisons entre les générations montrent des variations dans l'importance des dimensions des valeurs accordées aux enfants et dans les préférences concernant la taille de la famille. Les valeurs dont les enfants sont porteurs pour les jeunes
\end{abstract}

* Address for correspondence: David L. Sam, Department of Psychosocial Science, University of Bergen, Chrisitesgate 12, N-5015 Bergen, Norway. Email: david.sam@psysp.uib.no

The data for this study have been collected in South Africa as an adjunct to the "Value of Children and Intergenerational Relations" (VOC) project initiated by Professors Gisela Trommsdorff (Konstanz University, Germany) and Bernhard Nauck (Chemnitz University, Germany). The South African adjunct project was coordinated by Professor Karl Peltzer (University of the North, South Africa) and was funded by the University of the North. The research assistants Gladys Phaswana, Sabina Raphala, Mary Phosoko, and Cynthia Ledwaba are thanked for both data collection and entry. 
mères étaient liées au nombre d'enfants que ces femmes avaient et à leurs préférences relatives à la taille de la famille. La discussion sur les résultats tient compte de l'évolution du contexte sociopolitique de l'Afrique du Sud.

This study extends the ongoing studies on values of children and intergenerational relations into an African context with the following key questions: To what extent can the structure of values of children (VOC) identified in previous studies be found in South Africa and what are women's preferences regarding the size of small, large, and ideal families? The sample consisted of three cohorts of Black South African women from the Limpopo Province. Factor analyses showed that the dimensions of VOC found in South Africa are a conglomeration of different values. Identified dimensions were Sociall Emotional and Traditional/Utilitarian with respect to reasons for wanting children. Regarding reasons for not wanting children, Child as Source of Constraints and Constraints to Have a Child were identified. Intergenerational comparisons showed variations in the importance of value of children dimensions and in preferences regarding family size. Values of children of younger mothers were related to the number of children these women had and to their preferences regarding family size. The findings are discussed within the changing socio-political context of South Africa.

\section{INTRODUCTION}

Why do people have children, or more specifically what values do they assign to having children, and what are their preferences with regard to the size of a family? How are values of children and socio-demographic factors related to the size of a family? To what extent are values of children and preferences regarding family size stable across generations? We examine these questions using as our empirical base data gathered from over 800 Black mothers in South Africa, a country that has undergone a major sociopolitical change in recent years.

The question - why do people have children? - assumes that childbearing is a behavior that a couple or an individual makes active decisions about and initiates. A number of studies have suggested that in addition to biological factors, individual decisions have an important part to play in reproductive behavior (Kagitcibasi, 1982a; Trommsdorff, Zheng, \& Tardif, 2002). The general assumption is that the desire to have a child is based on one's motivations or more specifically the values one assigns to a child. Per definition, values serve as guiding standards for the selection of behavior, people, or events. The values a mother holds with respect to children might determine whether she will have a child in the first place, and/or the number of children she might want to have when other factors (e.g. the biological possibilities) permit it. As values are directly influenced by everyday experiences in changing ecological and socio-political contexts (Smith \& Schwartz, 1997), it is important that they are studied over a long period so as to capture the changes that are taking place within a specific cultural context. Accordingly, focusing on 
three cohorts of women (such as grandmothers, mothers with an adolescent child, and mothers with toddlers, as in this study) in a society such as South Africa (during the apartheid regime and its aftermath) is well suited.

Earlier studies examining the motivations people have for wanting children and/or the values they place upon them (VOC project-see Arnold \& Fawcett, 1975; Buripakdi, 1977; Fawcett, 1972; Kagitcibasi, 1982a) suggested that these could be either economic/utilitarian, psychological/ emotional, or social/normative values (Kagitcibasi, 1996). The economic/ utilitarian motive for wanting a child has been suggested as resting on the assumption that a child in the family will support the parents in their old age. In other words, having a child will ensure the economic survival of the family as a whole or the parents in particular. Psychological/emotional value for childbearing refers to the happiness, joy, and companionship that parents experience with having a child. Social or normative values refer to social expectation as well as the social advantages one may have for having children (e.g. the social approval and social status a married couple gets when they have a child; continuation of the family line as in the case of having a son). Concomitant to reasons for wanting a child are reasons for not wanting a child. These have become of great interest in recent years in view of the drastic decline in fertility rates in several Western countries (cf. Population Division of the Department of Economic and Social Affairs of the United Nations Secretariat, World Population Prospects, 2004). Reasons for not wanting a child have also been termed economic (i.e. the cost involved in bringing up a child), psychological (e.g. the stresses or discomfort of raising a child), and social (such as losing one's social status) values of children.

In the VOC project, value of children was construed as a socio-psychological construct. This was further conceptualised as a perceived value that exerts an influence on an individual's behavior. Specifically, value of children (as a socio-psychological construct) was seen as the intervening variable between antecedent background factors (such as age, family structure, and basic values) on the one hand, and the consequent outcome of fertility and reproductive behavior (such as the number of children, and the ideal size of a family) on the other hand (Kagitcibasi, 1982a, 1984). The consequent outcome behavior such as the ideal size of a family can be attitudinal in nature as this does not mean that one necessarily has the number of children he/she regards to be ideal, but is rather a desirable ideal.

The differentiation between these three types of values for wanting a child has proved useful in testing some of the theoretical assumptions between contextual and antecedent factors on the one hand and fertility behavior or attitudes towards the number of children one desires on the other hand. For instance, in less developed or in rural areas as compared to more developed or urban areas, parents tend to report more economic value of children as 
reflected in the extent to which parents invest in their own future in their child (Adjei-Mensah, 1997; Sam, 2001). In traditional patriarchic societies, pressure to have a son has been found to be related to female infanticide (Kohn, 1978). Moreover, Kagitcibasi (1982a, 1982b) found among her Turkish sample that while psychological value of children was negatively related with fertility behavior measured in terms of ideal size of the family and the number of children, the economic value of a child was positively related to the same behavior (Kagitcibasi, 1982a, 1982b). It was also found that parenting was more rule-oriented and authoritarian, and fertility was higher in less developed and rural areas compared to urban areas (Hoffman, 1987, 1988; Kagitcibasi, 1982a, 1982b).

A number of socio-demographic factors have been found to be related to one's values of children. In a study among over 1,700 women in Turkey, Kagitcibasi (1982a) found that the level of socioeconomic development of the area where the woman lives was inversely related to economic values of children, and positively related to the psychological values of children. Although the study did not find clear relations between Turkish women's SES and values of children, the general trend was similar to the socioeconomic development of the residential area (i.e. rural versus urban) (Kagitcibasi, 1982a). A positive relation was also found between university education and social value of children, suggesting that great respect is accorded women with both university education and children. Finally, the study also found that the values assigned to children were related to the number of children the woman had and/or regarded as the ideal number of children for the family. Specifically, the economic value of children was found to be positively related to family size, in the sense that each additional child was seen as an additional source of income. The relationship between the psychological values of child and family size, however, was somewhat different. A positive relationship between psychological value of children and the number of children - between one to two children - was found. However, this positive relationship could not be found as the family size increased. The relationship between social values of children and the number of children was similar to that found between number of children and psychological values of children. These findings seem to suggest that full social recognition and adult status may be achieved by having few children, and additional children may not necessarily increase a woman's social status.

Bearing in mind the socio-demographic variability in women's values of children, one question that this paper sought to answer was the extent to which socio-demographic factors affect women's preferences of family size, and the number of children they have. Furthermore we were interested in understanding how socio-demographic factors combine with values of children to affect the number of children women have and their preferences 
regarding family size. Since earlier studies on values of children were undertaken in non-African countries our primary interest here was directed to Africa, and in particular to South African women. In addition, we were interested in examining the stability of these values and the preferences regarding family size across generations taking into consideration the fact that the early studies were carried out over 20 years ago.

\section{THE SOCIO-POLITICAL AND DEMOGRAPHIC CONTEXT FOR FERTILITY BEHAVIOR IN SOUTH AFRICA}

Despite the classification of South Africa as a middle-income nation with a GDP per capita income of $\$ 11,290$ in 2001 (UNDP, 2003), the entire economy is divided along racial and gender lines where Whites and men generally have higher socioeconomic status compared with Blacks and women. Out of the total population of 44.8 million in 2001 (Statistics South Africa, 2003), of which four out of five are Black African, 95 per cent of the poor are Black African, 75 per cent are rural, and three provinces account for twothirds of the poor (Eastern Cape, Limpopo Province, and KwaZulu-Natal).

Comparatively, South Africa has the lowest fertility rate in sub-Saharan Africa. The fertility of the Black African population began to fall in the 1950s or early 1960s, far earlier than elsewhere in the region. By 1988, about 44 per cent of Black South African women were using contraception. Between 1970 and 1996, the total fertility rate among Blacks declined from 5.4 to 3.7 (Udjo, 2003). Census data for 1996 showed even lower fertility rates: 3.5 among Blacks and 3.2 for the entire country (Moultrie \& Timaeus, 2003).

Prior to HIV/AIDS reaching epidemic levels in South Africa, reproductive control and family planning in South Africa were tightly bound up with the policies and laws which entrenched social and economic inequality by race. Under the ideology of "separate development" the apartheid government, assuming power in 1948, expanded existing policy to ensure separateness of race and the appropriate distribution of black labor to serve white needs. All Blacks were assigned to one of ten homelands, or Bantustans, on the basis of home language. Only properly documented workers were allowed as "guests" in white areas. They were cordoned off in black townships usually located some miles away from "white" cities. Homeland policies and the migration system led to the prolonged absence of men, placing severe constraints on family building, reproductive decision-making, and family maintenance as women were left to fend for themselves and their children. This arrangement enabled employers to maintain a low-paid migrant labor force since employers did not need to provide for a whole family (Kaufman, 2000).

A transformation of gender relations within a racially discriminatory society gave rise to particular forms and patterns of proscriptions in everyday life for black women. The decline in fertility for African women was no 
doubt aided considerably by the well-resourced national program on family planning. The larger context of racial domination in the form of homeland policies, labor migration, and discrimination placed a great deal of strain on the social and economic relationships of women, men, and their families, with direct implications for childbearing and rearing.

The constraints shaping women's desire or ability to have fewer children have not disappeared with the advent of democracy in South Africa in 1994; many of the dynamics outlined here continue to operate on fertility decisionmaking (Kaufman, 2000). The efforts of well-funded family planning programs facilitated the availability of modern contraceptives, and the structure of statecontrolled labor patterns, residential policies, and the general incompatibility of women's employment and childbearing and rearing imparted a particular meaning to "benefits of smaller families", a meaning further influenced by the opinions and pressures of partners, elders, or in-laws (Kaufman, 2000).

In 2000, some women who were interviewed in the now Limpopo Province showed three levels of responsibility in their fertility behavior. While some indicated that they had no role in this behavior, others showed an emergent self-confidence, and still others radiated an obvious sense of control and power over their reproductive behavior (Kaufman, 2000). The most common reason given by women who did not want more children was economic circumstance, and many younger respondents indicated that they wanted to delay childbearing until they had completed their education (Kaufman, 2000).

The changing South African policy (with associated increased labor market opportunities for Africans, higher real wages, and shifts in the government's attitude to migration and urbanisation) presented opportunities for women (especially those in urban areas) to free themselves from traditional patterns of marriage and patriarchy. As a consequence, women could create (or, equally, be reduced to) alternative living arrangements in urban areas that were not as readily possible earlier, leading to a rise in the number of femaleheaded households and of other living arrangements that are not contingent on the presence of a husband (Moultrie \& Timaeus, 2001).

Women who live with relatives from their own generation have borne about a fifth fewer children than other women of the same age after controlling for the impact of household income, the woman's schooling, regional differentials, and urban-rural residence. Unmarried and separated mothers have about a fifth fewer children than married mothers of the same age (Moultrie \& Timaeus, 2001).

In summary, our primary goal in this study was to extend values of children studies in an African context, and in particular South Africa, with the following questions in mind: What values do South African women have for wanting/not wanting children? How many children do they have, and what are their preferences regarding family size? How do socio-demographic factors combine with values of children to affect the number of children they have and preferences with regard to family size? 


\section{METHOD}

\section{Participants}

Participants came from the Limpopo Province, South Africa, and all belonged to the Northern Sotho ethnicity. These were made up of three groups of mothers: 319 mothers who had at least one adolescent child $(M=$ $41.54 \mathrm{yrs}, \mathrm{SD}=6.86) ; 133$ grandmothers $(M=67.46 \mathrm{yrs}, \mathrm{SD}=9.51)$ and 369 mothers with a young child or toddler, i.e. $2-3$ years old $(M=26.74 \mathrm{yrs}$, $\mathrm{SD}=4.70$ ). While grandmothers and mothers with an adolescent child belonged to the same family, mothers with a young child were not related to any of the other groups of mothers. With regard to the number of children the mothers ever had given birth to, mothers with a young child had on average $M=1.50(\mathrm{SD}=.85)$ children, mothers with an adolescent child $M=4.17$ ( $\mathrm{SD}=2.03)$ children, and grandmothers $M=5.72(\mathrm{SD}=2.42)$ children. In terms of number of children, all three samples of mothers were statistically different from each other on the $p<.01$ level (overall effect $F(2,817)=385.32$, $p<.01$ ). Of course it has to be taken into account that these differences reflect the fact that these mothers are at different stages of their reproductive period.

While mothers with an adolescent child were either married or lived in cohabitation, over half of mothers with a young child were single (62.3\%), nearly half of the grandmothers were widowed (44.7\%), and 14.4 per cent of grandmothers were separated, divorced, or single. With respect to mothers with an adolescent child, single, separated, and divorced mothers were excluded from the study. Since the adolescent children of these mothers also took part in the study we wanted to ensure that all of them grew up within a two-parent family. However, data from adolescents are not considered in the analyses of the current article. Among all three groups of mothers, about half lived in a rural area, and the other half in an urban area. The educational background of the women varied considerably. Nearly half of grandmothers $(45.8 \%)$ had never been to school, but one grandmother had completed tertiary education. About one in four $(26.6 \%)$ of mothers with a young child had completed secondary school education. Only two mothers with a young child had had no education, and 13 of them had completed either a professional, post-graduate, or doctorate degree. With respect to mothers with an adolescent child, nearly a tenth had no formal education, and nearly 40 per cent had some secondary education. At the time of the interview, over a third of mothers with a young child $(38.3 \%)$, over half of mothers with an adolescent child (57.5\%), and one-fifth of grandmothers $(19.5 \%)$ were in an income paying job. With regard to perceived socioeconomic status measured on a scale from $1=$ low to $5=$ upper, mothers with a young child reported a mean of $M=2.33$ ( $\mathrm{SD}=.77$ ), mothers with an adolescent child a mean of $M=2.43(\mathrm{SD}=.86)$, and grandmothers a mean 
of $M=2.22(\mathrm{SD}=.83)$. Thus most women perceived themselves to have "lower middle" socioeconomic status, represented by the scale value of 2 .

\section{Measures}

The instruments used in this study were assembled by an international group of scholars for use in the cross-national study on values of children and intergenerational relations (Trommsdorff, 2001; Trommsdorff \& Nauck, 2003). For this part of the study, participants were required to answer questions on their reasons for wanting or for not wanting a child, as well as their preferences regarding different family sizes (small, large, and ideal family size). Questionnaires were translated from English into Northern Sotho and back-translated according to scientific standard procedures. Ethics clearance was obtained from the University of the North Ethics Committee, informed consent was taken from the interviewee, and confidentiality and anonymity were assured in the study.

\section{Values of Children}

The complete scale consisted of 48 items of which 23 were taken from the original VOC study (Arnold, Bulatao, Buripakdi, Chung, Fawcett, Iritani, Lee, \& Wu, 1975). In addition, 13 items were developed specifically for this study, and the rest taken from the Family and Fertility Survey (Pohl, 1995). Items were answered on a 5-point Likert scale ranging from "not important at all" to "very important".

Of the 48 items, 27 were framed to examine the reasons for wanting children (e.g. "Because it is a joy to have a small baby"), and the remaining 21 items were framed to underscore reasons for not wanting children (e.g. "Because a child is a lot of work and bother"). Because of the peculiar situation of grandmothers, such as having older children who are themselves mothers, some questions in the 48-item VOC scale were irrelevant to them. Thus, while mothers with an adolescent child and mothers with reasonsa young child had to answer all 48 VOC items, grandmothers had altogether 37 questions (23 dealing with reasons for wanting a child and 14 dealing with reasons for not wanting a child). An item such as "Because some of your older relatives feel that you should have more children" was excluded from their questionnaire.

\section{Number of Children Preferences and Regarding Family Size}

These involved direct specific questions about the number of children the women had ever given birth to as well as the number of children which in their opinion constituted a small family, a large family, and an ideal family. 


\section{Procedure}

Participants were chosen by multi-stage cluster in one of the six regions (one urban and one rural site) in the Limpopo Province. In each site, respondents were selected using a multi-stage sampling design. In each area a starting household was identified for inclusion in the sample. Additional households were selected using a pre-designed walk pattern. Next, within each selected household one eligible respondent was selected for interviewing. If the selected household contained more than one eligible respondent, the respondent who would have his or her birthday next was selected. Interviewers made up to three attempts to conduct an interview. Interviewing continued until the target number as specified in each site had been interviewed. None of the interviewees refused the interview. Five non-Northern Sotho-speaking participants were excluded from the study.

\section{RESULTS}

\section{Values of Children: The Factor Structure}

Instead of examining item for item with respect to reasons for wanting/ not wanting a child, we began analysing our data by finding the factor structure of values of children. Since we were interested in an empirical summary of the VOC items, a principal component analysis (PCA) was preferred to a traditional factor analysis (see Tabachnick \& Fidell, 2001). In an exploratory approach, we first did a PCA of the 27 reasons for wanting a child ("positive values of children") for mothers with a young child and mothers with adolescent child combined, and then separately for them.

In the PCA for the combined sample of mothers with an adolescent child and mothers with a young child three factors with an eigenvalue greater than 1 explaining 59.5 per cent of the variance emerged. Of the three factors, the first factor explained 45.8 per cent of the variance, while the second and third factor explained 7.4 per cent and 6.3 per cent, respectively. Since the first factor was very strong and we expected the factors to be correlated, an oblique oblimin-rotation was applied to the three-factor solution. The rotation led to an uninterpretable solution with the third factor made up of one item. Therefore, a two-factor solution was extracted, basically replicating the first two factors from the previous three-factor solution and explaining 53.2 per cent of the variance. These two factors were well interpretable from a content-perspective. The oblimin-rotated factors were correlated by .53. Since the same analyses carried out separately for mothers with an adolescent child and mothers with a young child yielded very similar results, we relied on the combined analysis only in the following. An examination 
TABLE 1

Principal Component Analysis With Oblimin-Rotation of Reasons for Wanting a Child Among Mothers With an Adolescent Child and Mothers With a Young Child Combined

\begin{tabular}{lrr}
\hline & Factors \\
\cline { 2 - 3 } & & \\
Items & 1 & 2 \\
\hline Because of the feeling of love that develops between a parent and a child. & .91 & -.21 \\
Because parenthood improves your standing and reputation among your kin. & .86 & -.11 \\
Because of the pleasure you get from watching your children grow. & .79 & .00 \\
Because any new family member makes your family more important. & .78 & -.07 \\
Because a child helps around the house. & .77 & -.10 \\
Because people with children are less likely to be lonely in old age. & .75 & -.13 \\
Because having children increases your sense of responsibility and helps you & .74 & -.02 \\
to develop. & & \\
Because it is fun to have young children around the house. & .72 & .18 \\
Because you want to share what you have with children. & .69 & .04 \\
Because it is a joy to have a small baby. & .68 & .22 \\
Because your life will be continued through your children. & .68 & .09 \\
Because raising children helps you to learn about life and yourself. & .68 & .04 \\
Because you can make new friends through your children. & .67 & .11 \\
To have someone to love and care for. & .66 & .03 \\
Because having children brings your husband and you closer together. & .66 & -.01 \\
Because having children intensifies contacts and communication with your kin. & .66 & .20 \\
To carry on the family name. & .63 & .14 \\
Because having children gives your husband/you more reason to succeed in & .59 & .17 \\
his/your work. & & .52 \\
Your children can help you when you're old. & .48 & .00 \\
When it is a duty to have children according to your belief. & .47 & .41 \\
To provide a companion for your child/children. & .37 & .35 \\
Because some of your older relatives feel that you should have more children. & -.06 & .93 \\
To have a boy/another boy. & -.07 & .89 \\
To have a girl/another girl. & .13 & .75 \\
To have one more person to help your family economically. & .11 & .49 \\
When your husband wants more children. & & .54 \\
To be sure that enough children will survive to adulthood. & & \\
\hline
\end{tabular}

Note: Items in bold were not included in further analyses due to cross-loadings. Items in italics were not used in the grandmothers' questionnaire.

of the factor loadings showed that two items showed high cross loadings and had to be excluded from subsequent analyses (see Table 1).

A similar approach was used to analyse the 21 reasons for not wanting a child. Here, four factors with eigenvalues greater than 1 appeared but the scree-plot clearly indicated that a two-factor solution was more appropriate. Thus, a two-factor solution was extracted with the first factor explaining 45.5 per cent and the second factor explaining 11.8 per cent of the variance 
TABLE 2

Principal Component Analysis With Oblimin-Rotation of Reasons for Not Wanting a Child Among Mothers With an Adolescent Child and Mothers With a Young Child Combined

\begin{tabular}{lrr}
\hline & \multicolumn{2}{c}{ Factors } \\
\cline { 2 - 3 } Items & \multicolumn{1}{c}{1} & \multicolumn{2}{c}{2} \\
\hline Because having a child causes problems and strains in your marriage. & .84 & -.03 \\
Because having children is a financial burden for the whole family. & .83 & .05 \\
Because you cannot spend as much time with your husband when you have & .83 & -.05 \\
children. & .81 & -.08 \\
Because children create problems with neighbors and in public. & .80 & .04 \\
Because it is hard to take proper care of both family and household. & .79 & -.05 \\
Because it is harder to hold a job. & .79 & -.03 \\
Because you lose contact with your friends. & .78 & -.10 \\
Because children are hard to discipline and control. & .77 & -.08 \\
Because a child is a lot of work and bother. & .76 & .03 \\
Because you are not as free to do what you want. & .75 & .15 \\
Because of the worries that children cause when they are ill. & .75 & -.11 \\
Because large families are not well accepted in society. & .69 & .03 \\
When being a mother is not well recognised by the people you deal with. & .66 & .18 \\
Because you cannot give enough care and attention to your children. & .59 & .23 \\
Because you are too concerned about the future your children will have. & .49 & .10 \\
Because of fear of pregnancy and childbirth. & -.11 & .86 \\
When your health does not permit it. & -.07 & .86 \\
When you arelyour husband is too old. & .02 & .71 \\
When you already have all the children you want. & .09 & .62 \\
When your husband does not want any children. & .12 & .59 \\
When your housing situation is not suitable. &
\end{tabular}

Note: Items in italics were not used in the grandmothers' questionnaire.

(together 57.3\%). Since correlated factors were expected here as well, oblimin-rotation was applied, resulting in factors correlated by .31. Again, the analyses for the separate samples of mothers yielded very similar results as compared to the combined analysis. See Table 2 for a summary of the two-factor solution for mothers with a young child and mothers with an adolescent child combined.

The two factors from the now 25 reasons for wanting a child (i.e. excluding the two items with high cross-loadings), Factors 1 and 2, were respectively termed: Social/Emotional Value of Children and Traditional/Utilitarian Value of Children. The two factors extracted from the 21 reasons for not wanting a child, Factors 1 and 2, were called Child as Source of Constraints and Constraints to Have a Child, respectively.

Separate PCAs were performed for grandmothers for their 23 reasons for wanting a child, and 14 reasons for not wanting a child, and their factor 
TABLE 3

Factor Names, Number of Items, and Internal Consistencies (Cronbach's Alpha) for Value-of-Children Dimensions

\begin{tabular}{llrlll}
\hline & & & $\begin{array}{l}\text { Mothers } \\
\text { with a } \\
\text { young } \\
\text { child }\end{array}$ & $\begin{array}{l}\text { Mothers } \\
\text { with an } \\
\text { adolescent } \\
\text { child }\end{array}$ & Grandmothers \\
\hline Reasons for wanting a child (VOC+) & N items & & & & \\
1 & Social/Emotional & $20(19)$ & .96 & .93 & .95 \\
2 & Traditional/Utilitarian & $5(4)$ & .86 & .76 & .83 \\
Reasons for not wanting a child (VOC-) & & & .96 & .97 \\
1 & $\quad$ Child as source of constraints & $16(11)$ & .92 & .96 & .80 \\
2 & $\quad$ Constraints to have a child & $5(3)$ & .78 & .79 & \\
\hline
\end{tabular}

Note: The figures in parentheses are the number of items used in creating grandmothers' indices.

structure was compared with the one obtained for mothers with an adolescent child and mothers with a young child. With respect to reasons for wanting a child a two-factor solution, accounting for 61.2 per cent of the variance, was extracted. Since quite identical factors compared to the mothers' solution emerged in the analysis for grandmothers, the subsequent analysis followed the factor solution obtained for mothers minus those items that were not in the grandmothers' questionnaire. With respect to reasons for not wanting a child, a two-factor solution was obtained according to scree-plot and eigenvalue criteria, accounting for 76.5 per cent of the variance. The oblimin-rotated solution exactly replicated the factor structure obtained for mothers so that we went on using the same factor structures for mothers and grandmothers using the items asked in the respective questionnaires. For reasons of space, the factor structures for grandmothers' reasons for wanting and not wanting children are not reported in detail.

For the resulting VOC dimensions Cronbach's alpha was calculated for all samples. The reliability analyses revealed that all the factors had acceptable internal consistency for all groups of women. These ranged from .76 to .97. See Table 3 for the exact reliability values and the number of items used in the respective indicators.

\section{Reasons for Wanting/Not Wanting a Child and Preferences Regarding Family Size: Comparisons}

Our next set of analyses involved comparing the three groups of mothers on their reasons for wanting/not wanting children and their views on family size applying one-way ANOVAs. Table 4 shows a summary of the results. 
TABLE 4

Value of Children and Preferences Regarding Family Size Among Three Groups of South African Women

\begin{tabular}{|c|c|c|c|c|c|c|c|c|c|c|c|c|}
\hline & \multicolumn{2}{|c|}{$\begin{array}{l}\text { Mothers with } \\
\text { a young child } \\
(\mathrm{n}=369)\end{array}$} & \multicolumn{2}{|c|}{$\begin{array}{l}\text { Mothers with } \\
\text { an adolescent } \\
\text { child }(\mathrm{n}=318)\end{array}$} & \multicolumn{2}{|c|}{$\begin{array}{l}\text { Grandmothers } \\
\quad(\mathrm{n}=133)\end{array}$} & \multirow[b]{2}{*}{$\mathrm{F}$} & \multirow[b]{2}{*}{$d f$} & \multicolumn{4}{|c|}{ Comparisons } \\
\hline & M & $(S D)$ & $M$ & $(S D)$ & $M$ & $(S D)$ & & & $1 / 2$ & $1 / 3$ & $2 / 3$ & $E t a^{2}$ \\
\hline \multicolumn{13}{|l|}{ Value of Children } \\
\hline Social/Emotional (+) & 3.95 & $(.88)$ & 4.01 & $(.84)$ & 4.35 & $(.77)$ & $10.73 * *$ & 2,815 & & $* *$ & $* *$ & .03 \\
\hline Traditional/Utilitarian $(+)$ & 3.20 & $(1.15)$ & 3.01 & $(1.14)$ & 3.48 & $(1.25)$ & $7.82 * *$ & 2,814 & $*$ & $*$ & $* *$ & .02 \\
\hline Child as source of constraints (-) & 1.67 & $(.71)$ & 1.70 & $(.97)$ & 1.68 & $(1.11)$ & 0.09 & 2,814 & & & & .00 \\
\hline Constraints to have a child (-) & 3.96 & $(.87)$ & 3.73 & $(1.11)$ & 3.32 & $(1.35)$ & $18.52 * *$ & 2,814 & $* *$ & $* *$ & $* *$ & .04 \\
\hline \multicolumn{13}{|l|}{ Family Size Indicators } \\
\hline Size of a small family & 2.64 & $(1.16)$ & 2.87 & $(1.33)$ & 2.93 & $(1.40)$ & $3.91 *$ & 2,814 & $*$ & $*$ & & .01 \\
\hline Size of a large family & 6.91 & $(1.91)$ & 7.07 & $(2.14)$ & 8.18 & $(2.79)$ & $17.19 * *$ & 2,811 & & $* *$ & $* *$ & .04 \\
\hline Size of an ideal family & 3.69 & $(1.20)$ & 3.59 & $(1.25)$ & 4.26 & $(1.90)$ & $11.83^{* *}$ & 2,814 & & $* *$ & $* *$ & .03 \\
\hline
\end{tabular}

Note: Post-hoc multiple comparisons are Least-Square Differences (LSD).

$+p<.10, * p<.05, * * p<.01$. 
With respect to reasons for wanting a child, grandmothers showed a significantly higher sociallemotional VOC as well as traditionallutilitarian $V O C$ than both samples of mothers. Additionally, mothers with a young child had a slightly higher traditional/utilitarian VOC than mothers with an adolescent child. With respect to reasons for not wanting a child, there were no differences among the three samples on the dimension child as source of constraints but significant differences on the dimension constraints to have a child: for mothers with a young child, constraints to have a child were more important as reasons for not having children than for mothers with an adolescent child and for grandmothers. Grandmothers were significantly lower than both samples of mothers on these dimensions. Though significant differences occurred regarding positive and negative values of children, effect sizes were small ranging from $\eta^{2}=.02$ to $\eta^{2}=.04$. Sociallemotional values were generally considered "important", traditionallutilitarian values "somewhat important", and child as source of constraints as "not important" by all samples. Constraints to have a child were considered "important" by both samples of mothers but only "somewhat important" by grandmothers.

With respect to the preferences regarding family size, significant differences were found for all measures, i.e. size of a small family, size of a large family, and size of an ideal family. Results showed that mothers did with a young child thought that there should be fewer children in a small family than did mothers with an adolescent child and grandmothers. For the size of a large family and of an ideal family, the pattern was somewhat different and the differences more pronounced: here, the two samples of mothers did not differ significantly from each other but both reported lower family sizes of large and ideal families than grandmothers. Effect sizes for these analyses were small as well, ranging from $\eta^{2}=.01$ to $\eta^{2}=.04$. Generally, a small family was considered to have between $c .2 .5$ (mothers with a young child) and 3 children (mothers with an adolescent child and grandmothers), a large family between $c .7$ (both mothers' samples) and 8 children (grandmothers), and an ideal family between $c .3 .5$ (both mothers' samples) and 4-4.5 children (grandmothers).

\section{Predicting Number of Children and Family Size}

Our final set of analyses examined how socio-demographic factors and values of children were related to the number of children a woman had ever given birth to and to mothers' preferences regarding family size. The number of children ever had can be seen as a direct measure of fertility while preferences concerning the number of children in small, large, and ideal families can be seen as a proxy to assess fertility-related values. These analyses were carried out only for the large enough two samples of mothers (the grandmothers' sample was too small to provide reliable and comparable 
results). To examine the effects of socio-demographic factors and the value of children separately, hierarchical multiple regression analyses were conducted. Socio-demographic factors were entered in the first step of the analysis, and values of children were entered in the second step.

The socio-demographic factors included region (coded: $1=$ rural; $2=$ urban), age, level of education (coded: $1=$ no schooling to $13=$ doctoral degree/professional), marital status (used only for mothers with a young child, and coded: $1=$ married/cohabiting; 2 = single), having an income paying job (coded: $1=$ yes; $2=$ no), and perceived socioeconomic status (coded: $1=$ low to $5=$ upper). For the dependent variables small, large, and ideal family size additionally the number of children already born to a mother was entered into the analysis to control for effects of the women's actual fertility. The values of children were the two positive dimensions sociallemotional and traditionallutilitarian and the two negative dimensions child as source of constraints and constraints to have a child. Separate analyses were conducted for the two groups of mothers and for the different outcome variables.

Results of the multiple regression analyses are summarised in Table 5. For mothers of a young child an overall significant effect on the number of children these mothers ever had occurred with $F(10,343)=20.35, p<.01$. In the demographic variables, age had a very strong positive effect due to the fact that the older mothers in this sample had more time to bear children than very young mothers. Furthermore, the level of education was negatively related to number of children and mothers who lived without a partner also had fewer children than those who were married or cohabiting. With regard to reasons for having a child, traditionallutilitarian VOC was positively related to number of children, and with regard to reasons for not having a child, constraints to have a child were also positively related to this fertility measure.

Concerning the prediction of small, large, and ideal family sizes the overall effects were all significant with $F(11,342)=5.62, p<.01, F(11,341)=$ $11.78, p<.01$, and $F(11,340)=7.49, p<.01$, respectively. The effects of the demographic variables showed that the number of children a mother had given birth to was positively related to all family size preferences; that is, women who had more children also thought that small, large, and ideal families should be larger than women who had fewer children. Age had a negative effect, showing that older as compared to younger women of this sample were inclined to say that small and large families should have less children. Mothers from an urban area judged small families to be smaller but large and ideal families to be larger than their counterparts from rural areas. While level of education had no effect on mothers with a young child's preferences regarding family size, marital status made a difference. Single mothers thought that large and ideal families should be smaller than married 
TABLE 5

Hierarchical Multiple Regression Analyses of Family Size Variables on Socio-Demographic Indicators and Values of Children Among Black South African Women

\begin{tabular}{|c|c|c|c|c|c|c|c|c|}
\hline \multirow{2}{*}{$\begin{array}{l}\text { Mothers with } \\
\text { a young child }\end{array}$} & \multicolumn{2}{|c|}{ No. children } & \multicolumn{2}{|c|}{ Small family } & \multicolumn{2}{|c|}{ Large family } & \multicolumn{2}{|c|}{ Ideal family } \\
\hline & $\beta$ & $\Delta R^{2}$ & $\beta$ & $\Delta R^{2}$ & $\beta$ & $\Delta R^{2}$ & $\beta$ & $\Delta R^{2}$ \\
\hline Step 1: Demographics & & $.33 * *$ & & $.10^{* *}$ & & $.19 * *$ & & $.18 * *$ \\
\hline No. of children & - & & $.31 * *$ & & $.31 * *$ & & $.21^{* *}$ & \\
\hline Age & $.52 * *$ & & $-.15^{*}$ & & $-.22 * *$ & & -.10 & \\
\hline Region & .02 & & $-.14^{*}$ & & $.16^{* *}$ & & $.29 * *$ & \\
\hline Level of education & $-.17 * *$ & & .03 & & .01 & & .01 & \\
\hline Marital status & $-.12 *$ & & $-.11+$ & & $-.20 * *$ & & $-.15^{* *}$ & \\
\hline Income paying job & $-.09+$ & & $.15^{*}$ & & .08 & & .02 & \\
\hline Socioeconomic status & -.05 & & .03 & & $.16^{* *}$ & & $.11^{*}$ & \\
\hline Step 2: Value of children & & $.04 * *$ & & $.05^{* *}$ & & $.09 * *$ & & .02 \\
\hline Social/Emotional (+) & -.02 & & $-.17 * *$ & & $-.23 * *$ & & $-.12+$ & \\
\hline $\begin{array}{l}\text { Traditional/Utilitarian } \\
(+)\end{array}$ & $.15^{* *}$ & & $.28 * *$ & & $.35^{* *}$ & & -.02 & \\
\hline $\begin{array}{l}\text { Child as source of } \\
\text { constraints }(-)\end{array}$ & .00 & & -.01 & & $-.11^{*}$ & & .03 & \\
\hline $\begin{array}{l}\text { Constraints to have } \\
\text { a child (-) }\end{array}$ & $.14^{* *}$ & & .03 & & $.11^{*}$ & & .07 & \\
\hline $\begin{array}{l}\text { Mothers with an } \\
\text { adolescent child }\end{array}$ & $\beta$ & $\Delta R^{2}$ & $\beta$ & $\Delta R^{2}$ & $\beta$ & $\Delta R^{2}$ & $\beta$ & $\Delta R^{2}$ \\
\hline Step 1: Demographics & & $.45^{* *}$ & & $.06^{* *}$ & & $.12 * *$ & & $.04+$ \\
\hline No. of children & - & & -.03 & & -.03 & & .05 & \\
\hline Age & $.47 * *$ & & .03 & & $.20 * *$ & & .03 & \\
\hline Region & $.14 * *$ & & .06 & & .01 & & .00 & \\
\hline Level of education & $-.22 * *$ & & $-.15^{*}$ & & $-.24 * *$ & & .05 & \\
\hline Income paying job & $.09+$ & & .06 & & .03 & & .00 & \\
\hline Socioeconomic status & $-.08+$ & & $.22 * *$ & & .07 & & $-.19 * *$ & \\
\hline Step 2: Value of children & & .00 & & $.12^{* *}$ & & $.03 *$ & & .02 \\
\hline Social/Emotional (+) & -.02 & & .02 & & .03 & & -.11 & \\
\hline $\begin{array}{l}\text { Traditional/ } \\
\text { Utilitarian }(+)\end{array}$ & .03 & & .06 & & .11 & & .07 & \\
\hline $\begin{array}{l}\text { Child as source of } \\
\text { constraints (-) }\end{array}$ & -.01 & & $.35^{* *}$ & & $.12+$ & & -.10 & \\
\hline $\begin{array}{l}\text { Constraints to have } \\
\text { a child (-) }\end{array}$ & -.03 & & .01 & & -.02 & & .00 & \\
\hline
\end{tabular}

$+p<.10, * p<.05, * * p<.01$.

and cohabiting mothers did, and the effect for small families was marginally significant. Mothers who had no income paying job considered small families to be larger than mothers with a job, but this rather weak effect could not be replicated for large and ideal family sizes. Finally, perceived 
socioeconomic status had a positive effect on their preferences regarding large and ideal family sizes. The higher the socioeconomic status the more children mothers considered to constitute large as well as ideal families.

With regard to the value of children variables, the two positive VOC factors showed effects in opposite directions: while sociallemotional VOC was negatively related to the preferences with regard to small and large families, traditionallutilitarian VOC was positively related. Thus, the more important social and emotional reasons to have a child were for mothers, the fewer children were believed to constitute a small and a large family. In contrast, the higher the importance of traditional and utilitarian values was, the greater the size of small and large families. For the negative VOC factors there were only significant results for the prediction of the size of a large family. The factor child as source of constraints was negatively related to this outcome variable, while the factor constraints to have a child showed a positive relation.

The analyses for mothers of an adolescent child yielded rather different results. For the dependent variable number of children ever had the overall effect was significant, $F(9,293)=26.84, p<.01$. Regarding effects of demographic variables, age had a positive effect on number of children, and more educated mothers had fewer children than those with less education. Furthermore, urban mothers had more children than rural mothers. There were no effects of value-of-children dimensions on the number of children. Regarding the prediction of family size preferences, the overall effects of the regression analyses were significant for the dependent variables size of a small family and size of a large family, $F(10,289)=6.23, p<.01$, and $F(10$, $288)=5.13, p<.01$, respectively; but not for the dependent variable size of an ideal family, $F(10,291)=1.72, p<.10$. Concerning demographic variables there were negative effects of level of education on size of a small family and size of a large family. Thus, mothers with higher education thought that there should be fewer children in small and large families than mothers with low education. There was a further positive effect of age on the size of a large family, and a positive effect of perceived socioeconomic status on the size of a small family. Regarding the effects of value of children dimensions there was a positive effect of the factor child as source of constraints on the size of a small family.

\section{DISCUSSION}

The current study had three aims: First, to explore the factor structure of the value of children construct for three samples of Black South African women from different generations. Second, to compare these three samples with regard to values of children and with regard to the preferences as to how many children should live in typical small, large, and ideal families. These measures can give us insights into fertility-related beliefs and norms 
beyond birth rates. Third, we explored the relationship between values of children and these fertility-related measures of family size, including the actual number of children born to a mother. The following discussion will proceed along this agenda.

\section{Reasons for Wanting and for not Wanting a Child}

According to the theoretical perspective of the earlier value of children studies there should be economic-utilitarian, social-normative, and emotional reasons to have children, and these or similar dimensions should be identifiable in numerous societies and cultures (Arnold et al., 1975). However, the dimensionality of VOC has never been cross-culturally established empirically. Thus, as a first step to find a possibly cross-culturally valid factor structure in the current multicultural project, it was important to explore whether and how the theoretically derived dimensions can be identified in the different cultures and samples.

For the South African case we believe that the previously reported psychological, social, and economic values of children (Kagitcibasi, 1982a) can be found among Black South African women, albeit not as clearly as expected. Our analyses suggest that these women's reasons for wanting children are a conglomeration of all three major reasons. The South African mothers and grandmothers interviewed in this study did not distinguish very much between emotional, social, and practical values. This can be seen in the very strong first factor that appeared in the PCA of the two samples of mothers. Though we decided to extract a two-factorial solution in the end, even a one-dimensional solution would have been possible when considering only factor loadings on the first factor and scale reliability. There was good reason to stay with a two-factor solution, however, because the items loading on the second factor were clearly different from those loading on the first factor in terms of the kinds of benefits children provide. On the first factor, all the emotional, social-normative, and practical benefits of a child combined, while the items of the second factor were clearly utilitarian, and also reflected the natural wish and/or simple necessity to have children as reflected in the items "To have another boy" and "To have another girl". Our inability to clearly identify economic/utilitarian, emotional, and social/ normative reasons for wanting children in South Africa may be a result of the unique socio-political situation of the country where women have not really had the liberty to decide on their fertility behavior.

There is less theory available regarding the dimensionality of the construct negative VOC (reasons not to have children). For Black South African women items describing several kinds of personal constraints and problems that arise when one has children all load on one factor. A second factor comprises items representing constraints to have children, such as bad 
housing conditions or bad health. Thus, these items depict conditions in the life of a woman that make it impossible or difficult to have children.

\section{Number of Children, Preferences Regarding Family Size, and the Value of Children}

Not only were there large variations in the number of children born to South African women in this study, but there were also variations in their reasons for having children and their preferences regarding different family sizes. Variations in the number of children born to South African women become clearer when one compares the number of children of grandmothers and mothers with an adolescent child and current fertility rates in South Africa. Generally, there seems to be a steady decline from one generation to the next. At the time of data collection the number of children of mothers with a young child was far below that of the current fertility rate in the country because the majority of them were still in their reproductive prime. There is therefore good reason to believe that mothers with a young child have generally not finished their reproductive period. This point is underscored by the fact that the ideal family size for mothers with a young child is consistent with current fertility rates (Moultrie \& Timaeus, 2003).

It may seem strange that the number of children of mothers with an adolescent child and of grandmothers is much higher than their preference regarding the ideal family size. It is possible that during their lifetime the older women changed their views as to what may constitute an ideal family size. It is also important to remember that the number of children these women gave birth to may not be the same as the number of living children since some of the children may have died due to the still high infant mortality rate of 56 infants in 1,000 (UNDP, 2003). Therefore, it is possible that these women's ideal family size actually reflects the number of their living children.

Even though there appears to be a consistent decline in the preferences regarding family size, the most significant difference occurred between mothers with young children and grandmothers, suggesting that these point to changes which, however, are quite slow. If this trend continues, it is possible that South Africa may, within the next 50 years, find itself with the same alarming fertility rates as occur in many Western countries (Population Division of the Department of Economic and Social Affairs of the United Nations Secretariat, World Population Prospects, 2004). In line with the decline of the preferences regarding family size across generations is the declining positive value of children. Grandmothers were significantly higher on both sociall emotional VOC and traditionallutilitarian VOC than both samples of mothers.

Further studies on the demographic development in South Africa should untangle the role of earlier Apartheid policies from current socio-political realities, and the impact of HIV/AIDS. In 2001, the peak adult (15-49 yrs) 
HIV prevalence rate was calculated to be 17.3 per cent in South Africa, with 2.34 million women and 1.71 million men living with HIV/AIDS (Rehle \& Shisana, 2003). Projections suggest a slight and gradual decline until 2010 $(15.2 \%)$, and this is further projected to remain relatively stable until the end of 2020 (15.7\% in 2020). By 2020, the total population of South Africa is expected to be 23 per cent less than it would have been in a "No-AIDS/ HIV-scenario". The rising numbers of AIDS-associated deaths, including women who are dying during their reproductive period, are expected to result in a significant reduction of the annual population growth rate $(0.2 \%$ in 2020). A negative population growth rate, however, is not expected for this projection period (Rehle \& Shisana, 2003).

\section{Effects of Demographic Factors and VOC on Family Size Indicators}

Our finding that the number of children is related to socio-demographic factors such as the mothers' level of education is consistent with Kaufman's (2000) finding in the Limpopo Province that young women delay childbearing in order to complete their education. Furthermore, young mothers had more children in stable relationships such as marriage and cohabitation. On the other hand, the fact that half of the mothers with a young child were still single at the time of the study suggests that marriage may take place after a woman has "proven" her maternal and reproductive abilities.

According to theoretical perspectives on VOC (Kagitcibasi, 1982a, 1982b), traditional, economic, and utilitarian reasons for having children should be positively related to fertility measures while psychological/emotional reasons should be negatively related to these indicators. The suggested pattern was found in our analyses of mothers with young children though the dimensions did not exactly correspond to the theoretically suggested structure of VOC. Sociallemotional VOC was negatively and traditionall utilitarian $V O C$ was substantially positively related to the size of a small or a large family. It is interesting that this pattern was not replicated with respect to the size of an ideal family. This may be due to a different social meaning of the size of an ideal family. Preferences regarding the ideal family size may be hardly influenced by individual values and attitudes because of a strong normative component of this concept.

\section{Limitations and Future Directions}

Before any firm conclusions can be drawn in this study, some methodological caveats need to be addressed. First, the database of this study is crosssectional instead of longitudinal which is not ideal when addressing issues of change. However, our data set goes beyond typical cross-sectional 
data because it consists of three cohorts of women including the two generations of grandmothers and mothers of an adolescent child. This has an added advantage of partly unconfounding cohort and time effects with respect to change.

Additionally, we are fully aware of the fact that there may be differences among women from different ethnic groups in South Africa. Whether our conclusions are valid for Black South African women beyond those of Northern Sotho ethnicity in the Limpopo Province is a question for future research.

Finally, it is worth noting that our study is retrospective, based on women who have children as opposed to childless women. Since the reasons for wanting a child may change once a woman becomes a mother, a prospective study that examines the reasons (young) childless women have for wanting a child prior to becoming mothers is highly recommended.

To conclude, this study gives first insights into the aspects of values of children and preferences regarding the family size of small, large, and ideal families in a sample of Black South African woman from three cohorts and two generations. South African women showed a structure of social/ emotional as well as utilitarian/traditional values. Preferences regarding the size of small, large, and ideal families declined across the two generations of grandmothers and mothers of an adolescent child. This result is in line with an overall slowly declining fertility rate in South Africa that is, however, still on a very high level. Finally, for the young mothers, values of children were related to preferences of family size in the predicted manner, suggesting that values of children are relevant for fertility-related decisions specifically for younger women in South Africa.

\section{REFERENCES}

Adjei-Mensah, S. (1997). Fertility change in a time and space perspective: Lessons from three Ghanaian settlements. Unpublished PhD Dissertation in Geography, Department of Geography, Norwegian University of Science and Technology, Trondheim, Norway.

Arnold, F., Bulatao, R.A., Buripakdi, C., Chung, B.J., Fawcett, J.T., Iritani, T., Lee, S.J., \& Wu, T.S. (1975). The value of children: Vol. 1. Introduction and comparative analysis. Honolulu, HI: East-West Population Institute.

Arnold, F., \& Fawcett, J.T. (1975). The value of children: Vol. 3. A cross-national study. Honolulu, HI: East-West Population Institute.

Buripakdi, C. (1977). The value of children: Vol. 4. A cross-national study. Thailand. Honolulu, HI: East-West Population Institute.

Fawcett, J.T. (Ed.) (1972). The satisfaction and costs of children: Theories, concepts and methods. Honolulu, HI: East-West Population Institute.

Hoffman, L.W. (1987). The value of children to parents. In C. Kagitcibasi (Ed.), Growth and progress in cross-cultural psychology (pp. 159-170). Berwyn, IL: Swets \& Zeitlinger. 
Hoffman, L.W. (1988). Cross-cultural differences in child rearing goals. In R.A. LeVine, P.M. Miller, \& M. Maxwell West (Eds.), Parental behavior in diverse societies (pp. 99-122). San Francisco, CA: Jossey-Bass.

Kagitcibasi, C. (1982a). The changing value of children in Turkey. Honolulu, HI: East-West Population Institute.

Kagitcibasi, C. (1982b). Old-age security value of children: Cross-cultural socioeconomic evidence. Journal of Cross-Cultural Psychology, 13, 29-42.

Kagitcibasi, C. (1984). Socialization in a traditional society: A challenge to psychology. International Journal of Psychology, 19, 145-157.

Kagitcibasi, C. (1996). Family and human development across cultures: A view from the other side. Mahwah, NJ: Erlbaum.

Kaufman, C.E. (2000). Reproductive control in apartheid South Africa. Population Studies, 54, 105-114.

Kohn, M. (Ed.) (1978). Infanticide and the value of life. Amherst, NY: Prometheus Books.

Moultrie, T.A., \& Timaeus, I.M. (2001). Fertility and living arrangements in South Africa. Journal of Southern African Studies, 27, 207-223.

Moultrie, T.A., \& Timaeus, I.M. (2003). The South African fertility decline: Evidence from censuses and a demographic and health survey. Population Studies, 57, $265-283$.

Pohl, K. (1995). Design und Struktur des deutschen FFS. Materialien zur Bevölkerungswissenschaft: Familienbildung und Kinderwunsch in Deutschland (Heft 82a). Wiesbaden, Germany: Bundesinstitut für Bevölkerungsforschung.

Population Division of the Department of Economic and Social Affairs of the United Nations Secretariat, World Population Prospects (2004). The 2002 revision and world urbanization prospects: The 2001 vision. Retrieved 17 June 2004, from http://esa.un.org/unpp.

Rehle, T.M., \& Shisana, O. (2003). Epidemiological and demographic HIV/AIDS projections: South Africa. African Journal of AIDS Research, 2, 1-8.

Sam, D.L. (2001). Values of children: Effects of globalization on fertility behavior and child rearing practices in Ghana. Research Review, 17, 5-16.

Smith, P.B., \& Schwartz, S. (1997). Values. In J.W. Berry, M.H. Segall, \& C. Kagitcibasi (Eds.), Handbook of cross-cultural psychology: Vol. 3. Social behaviour and applications (pp. 77-118). Boston, MA: Allyn \& Bacon.

Statistics South Africa (2003). South African Census 2001. Pretoria, South Africa: Statistics South Africa.

Tabachnick, B.G., \& Fidell, L.S. (2001). Using multivariate statistics. Boston, MA: Allyn \& Bacon.

Trommsdorff, G. (2001). Values of children and intergenerational relations: A crosscultural psychological study. Retrieved 25 March 2002, from University of Konstanz, Department of Psychology, Developmental and Cross-cultural Psychology. Web site: http://www.uni-konstanz.de/developmental-psychology/vocpsycholgieaspoects.pdf.

Trommsdorff, G., \& Nauck, B. (2003). Value of children in six cultures: Eine Replikation und Erweiterung der "Value-of-Children-Studies" in Bezug auf generatives Verhalten und Eltern-Kind-Beziehungen. Antrag an die DFG [Value of children in six cultures: A replication and extension of the "Value-of-Children-Studies" with respect to generative behavior and parent-child relationships. Proposal to 
the German Research Council (DFG)]. Unpublished manuscript, University Konstanz, Konstanz, Germany.

Trommsdorff, G., Zheng, G., \& Tardif, T. (2002). Value of children and intergenerational relations in a cultural context. In P. Boski, F.J.R. Van de Vijver, \& A.M. Chodynicka (Eds.), New directions in cross-cultural psychology (pp. 581-601). Warsaw, Poland: Polish Psychological Association.

Udjo, E.O. (2003). A re-examination of levels and differentials in fertility in South Africa from recent evidence. Journal of Biosocial Science, 35, 413-431.

UNDP (2003). Human development report 2003: Millennium development goals: A compact among nations to end poverty. New York: Oxford University Press. Retrieved 15 February 2004. 